\title{
Administrative Procedures and Processes
}

\author{
Jan Ziekow
}

\section{INTRODUCTION}

The title of this chapter, which distinguishes between administrative procedures and processes, already indicates that the view of the procedural 'working' side of the administration is of central importance for the respective administrative cultural understanding. The German understanding of administration is strongly determined by organisation. In this sense, the administration is an organisation subdivided hierarchically and structured by the normative assignment of functions and responsibilities into units of expertise, the 'organisational structure', the framework for the interactions and actions of the administration. Because of this organisational reference, the entirety of the procedures and processes of the administration is called the 'process organisation'. This differs from an understanding that summarises the processes of the administration as 'business processes' and is more process-oriented. However, in the course of New Public Management a much stronger process orientation of the German administrations has taken place (cf. Lenk 2012).

J. Ziekow $(\bowtie)$

German Research Institute for Public Administration, Speyer, Germany e-mail: ziekow@foev-speyer.de

(C) The Author(s) 2021

S. Kuhlmann et al. (eds.), Public Administration in Germany, Governance and Public Management, https://doi.org/10.1007/978-3-030-53697-8_11 
While the term procedure has functional connotations and includes aspects such as ensuring transparency, accountability and participation, provision of legitimacy, and ensuring rights and the correctness of the result (Ponce 2005: 552-553), process refers to the totality of administrative workflows for preparing and delivering a service.

\section{Classification of Processes}

The literature on the processes of public administration makes a distinction between different forms of process, based predominantly on the process map known from process management with the three stages of core, management and support processes (cf. Bundesministerium des Innern Bundesverwaltungsamt 2018: 4.2; KGSt 2011: 16):

- The core processes of companies are the value-added processes directly related to the customer's wishes that 'give the company its face'. In public administration, this means the service provision processes directly serving the realisation of the unit's strategic goals, usually delivering services to persons outside the organisation.

- Support processes are usually intra-organisational processes that provide the resources or services needed to perform the core processes.

- Management processes-also referred to as leadership or control processes - are processes that are not directly related to actual service provision, but serve to formulate the strategic goals of the organisation and set and enforce standards for performance and a framework for the other types of process.

Not completely identical to the above categorisation is the classification of processes in relation to the boundaries of the respective administrative organisation:

- Processes that are exclusively within the respective administrative organisation, for example those that take place in a ministry, are intra-organisational. These are support and management processes.

- Inter-organisational processes are processes between two or more administrative organisational units. These can be structured at the same level in the form of cooperation and support, or hierarchically. As a rule, these are support and management processes, but 
inter-organisational core processes in cooperative service provision are also possible.

- Extra-organisational processes are performed by an organisational unit of the administration to persons or companies outside the administration. These are, almost without exception, core processes to the clients of the administration. The procedures in which these extra-organisational core processes run are usually summarised under the term administrative procedures (see Sect. 1 above).

The presentation of the administrative procedures and processes in this chapter follows the above distinction according to the organisational reference point. Since the German administration is to be classified as a legalistic type of administrative culture, the process of administration in Germany is largely regulated by laws and subordinate acts.

\section{Extra-Organisational Procedures}

Extra-organisational procedures relate to the administration's 'external' actions, that is those oriented towards citizens and businesses. These actions are to be classified as core processes, as these interventions towards citizens and companies are usually among the core tasks of the respective administrative unit. The conduct of extra-organisational procedures is strongly determined by the interaction with the point of reference of the process, that is the citizen or company. Therefore, for a comprehensive understanding of the extra-organisational procedures in addition to the actual processes of 'outward' service delivery (see Sect. 3.1 below), the communication between the administration and the recipients of the services (see Sect. 3.2 below) is also of importance. The prerequisite for successful communication is information. Therefore, transparency and information are conditions of success for the provision of services by the administration (see Sect. 3.3 below).

\subsection{Service Delivery Processes}

The discussion about the introduction of New Public Management to the German administration has led to a shift towards a broader understanding of the notion of administrative performance, brought about by product orientation as part of New Public Management. This has established an 
understanding that defines 'service' as the administration's output created to accomplish each task.

Accordingly, the circle of what is regarded as a 'service' of the administration is large. The spectrum includes financial support and consultations, but also rules and prohibitions, their enforced execution and much more. All services at all levels of the German administration are recorded in a central service catalogue (LeiKa).

The understanding of services as output generated by the administration and the great heterogeneity of services have focussed attention on the need for a differentiated view of this process of output generation. In order to reduce the complexity associated with it for the individual administrations and enable role-model learning, the project of a National Process Library was initially pursued. As an online tool, the aim of this National Process Library was to successively compile and retrieve as many process models as possible at all administrative levels and according to certain order patterns. Since no agreement could be reached on the financing modes, the further development of the National Process Library was discontinued in 2015. Notwithstanding, process libraries are still operated by individual federal states and-for the municipal administrations-by the Local Governments' Joint Agency for Administrative Management (KGSt).

An awareness that providing high quality administrative services and customer satisfaction requires the ability of administrations to develop and establish business processes tailored to their needs has evolved. This has not been ignored but, on the contrary, has been supported by the standardisation and modularisation of processes. This makes it possible, at least for comparable services or process elements, to reduce complexity and make use of proven standard process elements. The digitalisation of the administration makes it possible to call up standard descriptions and modules with regard to the respective service and modify them to measure. In order to enable administrations either to fully model business processes or to modify standardised elements for the individual service, business process management with the goal of optimising business processes has been established at all administrative levels. In addition, business process management is understood as a means of procedurally implementing the digitalisation of administration.

At the level of the federal administration, this increased 'thinking and acting in processes' has been triggered by a project for joint and integrated process optimisation. The Federal Ministry of the Interior (BMI) has initiated the formation of a process management network consisting of 
process experts from various federal administrations who discuss problems of process management and successful solutions. Among other things, this network has developed a guide to strategic process management for senior managers in public administration (Netzwerk Prozessmanagement 2018). Corresponding process management instructions are available in various federal states. For the municipal level, the KGSt had already presented guidance on process management in 2011 (KGSt 2011).

In addition to establishing and consistently implementing business process management, recent efforts with regard to public service delivery processes have focussed on increasing efficiency in the interests of citizens and businesses and on the digital architecture of business processes. The requirements of the European Union Services Directive on 'single contact' have reinforced a trend towards the introduction of front office/back office structures. This trend already existed at the local level in the form of local 'one-stop shops' for administrative services that were designed to facilitate access for citizens. The function of a local one-stop shop for administrative services is to bundle communication with citizens when using municipal services, such as the renewal of ID cards and the application for social benefits. The fact that only one point of contact for all citizens' matters, which is close to their residences and which will promptly take care of their requests, makes the administration more citizen-oriented. In the course of the digitalisation of the administration, electronic service portals have supplemented the local one-stop shops for administrative services, through which many processes between the citizens and the municipal administration can be handled web-based.

For the digitalisation of the processes, see Sect. 3.2 below.

\subsection{Communication}

Efforts in Germany to make communication between the administrations and their customers more citizen-friendly and faster by digitalisation initially focussed on asynchronous communication. In this respect, the goal has been to improve the low communication security of a simple email through the establishment of so-called trust services. A central measure has been the establishment of De-Mail services, which may only be offered by accredited companies. However, the use of De-Mail services has remained low in practice. EU-wide safety standards are set by European Regulation (EU) No. 910/2014 on electronic identification and trust services for electronic transactions in the internal market. 
A fundamental new approach has been taken with the 2017 Online Access Act $(\mathrm{OZG})$. It stipulates that all administrative services must be offered via electronic administrative portals. However, this does not have to be done exclusively. In addition, the administrations can continue to provide their services in other forms of communication using the multichannel concept. To facilitate communication for the users, the portals of the individual administrations remain in place but are linked to form an integrated portal network. All administrative services accessible in the portal network are identified uniformly via an individual user account. An electronic mailbox is connected to the user account for secure communication between the authority and the user (cf. Martini and Wiesner 2018; for the digitalisation of public administration cf. Chap. 19, Appendix).

\subsection{Transparency and Information}

Both within and outside a specific administrative procedure, public authorities are obliged to provide information to citizens. This aims to ensure both the general transparency of the administration and the citizens' confidence in it as well as the protection of the subjective rights of those involved in an administrative procedure.

Within a specific administrative procedure, which should end with a decision by the authority:

- There is the right of the affected party to a hearing by the authority. This right serves to ensure a fair procedure. The person concerned must be given the opportunity to speak before a decision concerning his or her rights is taken, so as to be able to influence the proceeding and its outcome (Section 28 of the Administrative Procedures Act-APA).

- The parties have the right of access to files. This serves to ensure the realisation of the legal hearing and observance of the 'equality of arms principle' by the participants (Section 29 APA).

- In certain proceedings, an applicant may determine the status of the application processed by the authority via the Internet at any time.

Even outside concrete administrative procedures, various information is provided by the authorities to improve transparency and the information situation (cf. Müller et al. 2019): 
- Under the Freedom of Information Act (IFG), every citizen has a subjective right of access to official information from any authority. In certain cases, this right does not exist if it is necessary for the protection of particular public interests, the protection of the regulatory decision-making process, the protection of personal data or the protection of business or trade secrets. The right of access to information can be enforced in court.

- In addition to the right of access to information, there are more recent transparency regulations in the federal states (Länder) of Hamburg and the Rhineland-Palatinate. In these states, public authorities are required to make certain information that is relevant to the public accessible to everyone via a transparency platform on the Internet.

In addition, there is the nationwide metadata portal GovData where the open data provided by federal, state and local governments can be accessed. Various federal states and municipalities also operate their own open data portals.

\subsection{Law}

The administrative processes that transcend the intra-organisational and inter-organisational area and address citizens or businesses are almost completely regulated. The reason lies directly in the German understanding of the constitutional state.

\subsubsection{Functions of Administrative Procedure Law}

Because the state is more powerful than all other actors, mere private law is not an effective means of protecting the freedom of the citizen against the state. This requires a special law for the containment of state power in the form of public law. In Germany, special importance is assigned to general administrative procedure law. Located between the Basic Law and sector-specific special administrative law, the Administrative Procedures Act (APA) functions as a transmission belt, which forwards the standards of constitutional law to daily administrative practice. The APA represents the stabilising backbone of administrative law as a whole. It systematises the central legal institutions, so that regardless of which specific administrative law applies in a given individual case, the same basic patterns are accessed. This establishes transparency and predictability. 
In the German federal system, the individual federal states and the federal government respectively regulate the administrative procedures with an individual administrative procedures act for their own administrations. Except for minor deviations, however, these laws contain the same procedural rules.

\subsubsection{Structures and Principles of Administrative Procedure Law}

In accordance with its aim to contain the power of the state, the APA applies only to sovereign acts of the state, that is acts in which the state relies on public law. If the state acts as a private citizen under private law, the APA is not applicable. Even when the state does act under public law, the APA only applies if the action intended by the administration takes the form of an administrative act or a public law contract $v i s-\grave{a}$-vis the citizen. These are the two most important forms of action by the administration, which are connected with special impacts. The principle of freedom of form should enable the administration to carry out administrative procedures in a simple, expedient and expeditious manner in the interests of citizens and businesses. Only specific decisions are governed by specific procedural rules.

Despite the principle of freedom of the administrative procedure, the APA contains various provisions that the administration must adhere to in order to respect the requirement of a fair trial and protect the interests of the parties (cf. Rowe and Winterhoff 2001). These provisions are mainly:

- The investigative or ex officio investigation principle. On the one hand, this central procedural principle results from the rule of law, in particular the principle of the legality of the administration because it is about clarifying the facts in the public interest. On the other hand, what is behind the principle of ex officio investigation is the legal protection of those involved, in particular the citizen. For this reason, Section 24 APA expressly states that the authority must also take into account all circumstances that are favourable to the participants.

- The duty of support and care of the authority to the participants of the proceedings. The civil servant should not only be a servant of the state but also act as a helper for the citizen to create 'equality of arms' for the parties and prevent the realisation of rights from failure due to ignorance, inexperience or awkwardness in dealing with authorities.

- The right to be heard by the authorities (cf. Sect. 3.3 above). 
- The right of access to the files (cf. Sect. 3.3 above).

- The legal bounds of discretion of the authorities. At its discretion, the administration may only decide if a law has allowed this for the specific decision in question. Even if this is the case, the discretion of the authority is not unlimited, but may only be exercised within the framework laid down in the APA.

- The confidence protection principle. This principle protects the person concerned by ensuring that unilateral revocations of decisions already taken by the authorities are not revoked without taking account of the person's trust (legitimate expectation) in the existence of the decision.

\subsubsection{Reform Discussions and Recent Developments}

More recent discussions and developments with regard to administrative procedure law can be grouped together into three blocks: firstly, changes directly related to the APA; secondly, procedural regulations in the field of digitalisation; and thirdly, considerations at the level of the European Union.

Discussions concerning the amendment of the APA have related, among other things, to the participation of citizens and the acceleration of approval procedures:

- The result of the discussion to strengthen citizen participation was the inclusion of a provision in Section 25 (3) APA, according to which the public is to be involved in major industrial and transport projects before the permit application is submitted to the authority. This provision is significant because, according to earlier German understandings, the general public was not involved in an authorisation procedure, only those whose own rights were actually affected. The public also includes associations which represent the interests of environmental issues and are officially recognised for that purpose (Section 73 (4) APA, Section 2 of the Environmental Appeals Act [UmwRG]).

- For several decades now, Germany has been debating whether the granting of permits for the construction of economic or infrastructure projects takes too long, thus impairing economic development. The most recent law of this kind is the 'Law on the Acceleration of Planning and Approval Procedures in the Transport Sector', which came into force at the end of 2018. 
The second big block of recent developments is the discussion about the legal regulation of digital administrative procedures. In the legalistic German administrative culture, there is a high degree of consensus that at least the basic rules of digital administrative procedures should be regulated by law. These regulations have been partly laid down in the APA, and partly in special procedural laws. In particular, basic rules were added to the APA relating to the conditions under which electronic communications can achieve legally binding effects in administrative proceedings (Section 3a APA), the duty to take account of important information from participants in automatic electronic procedures (Section 24 (1) APA), the legal equality of an automatically issued administrative act with a manmade administrative act (Section 35a APA) and the possibility of notification of an administrative act via retrieval from an Internet portal (Section 41 (2a) APA).

Added to this are the e-government laws, that is the acts to promote electronic government for electronic administration issues. These special procedural laws have been adopted for both the federal administration and the administrations of most Länder. Among other things, they include provisions on the electronic submission of documents in the administrative procedure, electronic record keeping and access to files, and open data (on the Online Access Act (OZG) cf. Sect. 3.2. above).

A third major thread of discussion is the relationship between German administrative procedure law and the law of the European Union. A new impetus for the importance of the European idea for national administrative procedure law has been provided by a Europe-wide research network, the Research Network on EU Administrative Law (ReNEUAL). After several years of work, this network has developed the 'ReNEUAL Model Rules on EU Administrative Procedure' from an analysis of EU law and the administrative law of the Member States. The approach of the ReNMR corresponds to a great extent to the development of German administrative procedure law. The principle of analysing the different legal subsystems and, through comparative analysis, identifying congruent components and extracting the best elements in order to establish an optimal system at a higher level, one which subsequently establishes a set of propositions to guide the further development of the different legal subsystems, is deeply rooted in the tradition of German federalism. The model rules have initiated reflection on the revision of German law in various regulatory areas of administrative procedure law. 


\section{Intra-Organisational Processes}

Intra-organisational processes designate support and management processes within the respective administrative unit. They serve to set the strategic goals and framework for the organisation and its task fulfilment as well as support the execution of the core processes.

\subsection{Management and Support Processes}

In the course of the discussion about gearing German administrations more strongly to the principles of New Public Management, the instruments associated with management and support processes have now been further incorporated into the administration. This concerns, for example, the instrument of controlling, which has been implemented in municipal financial reporting at local authority level with the change from cash-based accounting budgetary management to a product-based budget. Since these questions are dealt with in more detail in the Chap. 16, this will not be discussed in detail here. The same applies to performance management, which is also the subject of the Chap. 16.

Quality management is understood as a comprehensive procedural approach, for which German public administrations rely on two basic models (Löffler 2018: 6-10):

- The series of standards ISO 9000 et seq. of the International Organisation for Standardisation (ISO), implemented in Germany in the corresponding standards of the German Institute for Standardisation (DIN), with the core elements being customer orientation, leadership, inclusion of persons, process-oriented approach, improvement, evidence-based decision-making and relationship management, formulates the requirement for an external certification of quality management.

- The Common Assessment Framework (CAF), on the other hand, is a quality assessment instrument in the form of a self-assessment tool, agreed for the civil service of the EU Member States in 2000. It aims to develop and strengthen the administrations' ability for selfassessment in a comprehensive internal communication process and to develop improvements. 
Quality management is now carried out in many German authorities, both at the level of the local governments and the administrations of the federal states as well as the federal government. The main challenge is to implement the improvement requirements identified by quality management (Löffler 2018: 10).

It is, therefore, essential that change management should also be part of the quality management process right from the start and that the change process be developed out of the quality management implemented. However, change management also has significance beyond quality management. In view of the intense pressure for change to which the administrations are being subjected, not only through digitalisation but certainly also because of it, methods of change management are, at any rate, widely used in major change processes in German administrations (Die Bundesregierung, Change Management 2019). Recent approaches emphasise above all the necessary change in the thinking of administration employees.

The greater involvement of project-related thinking with the associated project management in German administrations is reflected by a situationrelated relativisation of the line organisation structure with a fixed assignment of tasks. This is especially the case for temporary tasks with a high degree of complexity. As a rule, the Joint Rules of Procedure of the Federal Ministries (GGO) provide for the establishment of project-related management by specially established project teams in such tasks (Section 10 (2) GGO). In 2013, the federal government introduced the 'Practical Guide to Project Management for Public Administration'.

\subsection{Knowledge Management}

The traditional knowledge management of the administration has consisted mainly in archiving and file systems and the individual knowledge of the employees. For almost every German administration there are filing orders or similar administrative instructions that specify in which system the information available to the administrations must be stored in file form so that they can be retrieved as simply as possible.

Due to digitalisation, knowledge management has also undergone a major transformation. First, the knowledge available and the quantity of information and data to be processed by the administrations have grown exponentially. Second, the requirements related to the speed of access and retrieval of knowledge have increased significantly. Third, IT solutions 
provide the ability to integrate and prepare large pools of knowledge tailored to the needs of each administrative unit.

An empirical study compiled in 2013 showed considerable deficits in the knowledge management of the authorities at that time and room for improvement in the introduction of knowledge management systems (Materna GmbH and Hochschule Harz 2013: 65-67). Since then, a great deal of effort has been made to provide knowledge management solutions tailored to the needs of each agency, thereby anchoring knowledge management broadly in the administration. For example, the Federal Administration Office, a superior federal authority with service functions for the federal administration, offers an intranet solution (OfficeNet) for federal authorities with the option of agency-specific configuration. The authorities using OfficeNet work together in a specialist network and exchange their experiences and perspectives on possible further developments both in workshops and via an online platform. For municipal administrations, the KGSt has a knowledge management best practices database.

From 2020 onwards, the federal authorities are subject to the obligation under Section 6 of the E-Government Act (EGovG) to keep their files electronically. For the period ending 2019, a software solution was initially introduced in several federal agencies as part of a pilot project. In the second phase of the project, the e-file solution provided by the Federal Information Technology Centre, the IT service provider of the federal government, will be introduced for all federal authorities deemed suitable for this purpose based on a capability maturity model.

\subsection{Law}

The processes within a single administrative unit are generally not governed by legislation in the strict sense (laws enacted by parliament or legal authorisation). The normative control of the internal administrative procedure is governed by administrative rules adopted by the executive itself.

In certain cases, however, rules related to questions on administrative internal processes are established through formal law. These questions concern important preconditions for proximity to the citizen and speed of administration. An example of this is the legal obligation to keep all files electronically (cf. Sect. 4.2 above). 


\section{Inter-Organisational Processes}

Inter-organisational processes take place between different administrative organisational units, regardless of whether they are in a horizontal or vertical (hierarchical) relationship. These processes serve to ensure and improve the effectiveness and efficiency of task performance and the lawfulness of administrative action. To this extent, processes between administrative units can be divided into three categories: communication and cooperation, the support of one administrative unit by another outside cooperative relations and the supervision of one administrative unit by another.

\subsection{Inter-Organisational Communication and Cooperation}

Communication and cooperation between different administrative units take place in daily work to meet many different kinds of requirements and in various forms. It is an essential element of an active authority culture that authorities inform one another and, if necessary, cooperate to fulfil their tasks more effectively and efficiently. In this respect, two groups of communication and cooperation can be distinguished:

- The communication or cooperation is related to the processes of service provision by at least one of the communicating or cooperating authorities. In this regard, we speak of performance-related cooperation.

- The cooperation is generally for mutual information between authorities. This communication also serves to improve service provision, but only indirectly. Examples are joint meetings or inter-ministerial informal permanent working groups, as set up in Germany both between the federal ministries for the coordination of government work at the working level and in committees on which the relevant ministries of all federal states are represented. These forms of cooperation are not directly related to the process.

As far as performance is concerned, a distinction can be made between communication and cooperation:

- Communication should be understood as the interaction between several administrative units in the context of a specific process of service provision. 
- Cooperation, by contrast, means that formal or informal arrangements are established, independent of a concrete service delivery process, and that after their establishment they are then process owners, or at least contribute to the process.

\subsubsection{Performance-Related Communication}

In the context of a concrete service provision process, authorities communicate to ensure that all the aspects that are important in that process are incorporated into it and taken into account in the provision of services. This is usually about technical aspects, for example where environmental authorities are involved in approval procedures for industrial plants, or about the impact of the outcome of proceedings on the activities of the administrative unit concerned. The latter, for example, is when the municipality has to be involved in the approval of construction projects by state authorities as this limits the ability of the municipality in terms of future development planning.

On the one hand, this communication can be informal. In this case, the competent authority asks another authority for information which the requesting authority does not have, for example information to assess the impact of certain environmental emissions. On the other hand, the communication is formal if different authorities are required by law to be involved in the service delivery process. The significance of the part contributions provided for by law may differ:

- Involvement is a contribution by an authority to a procedure for which another authority is responsible if the intention is to introduce a specific technical aspect into the procedure. The responsible authority is not bound by the view of the other authority.

- This is different to co-decision. Here, the partial contribution of the other authority is binding for the responsible authority.

\subsubsection{Performance-Related Cooperation}

For cooperation between different administrative units aimed at improving the fulfilment of the tasks of the participating units with regard to specific service provision processes, two basic cases can be distinguished:

- The cooperation provides internal services to the administrative units involved in the cooperation so that they can deliver their services more effectively and efficiently. 
- The cooperation concerns not only internal support processes but also-directly-the service provision processes towards citizens and companies.

For the first case group, the provision of performance-related support through cooperation, the term shared service (centre) is generally used. Such shared services exist in Germany both horizontally and vertically (Schuppan 2018). In horizontal cooperation, administrative organisations cooperate at the same level with mostly identical tasks. Especially at municipal level, there are numerous examples in the back-office area. They concern, for example, the operation of a common building yard or joint legal department by several municipalities. By far the most important example, however, is shared services in the area of IT. Here a common IT service centre for several municipalities is set up. Vertical cooperation across multiple levels of administration is also found, especially in the IT sector, in the form of a common IT service centre of municipalities with one or more federal states. An example of such a cooperation is the information service provider Dataport. Knowledge sharing, or crossorganisational knowledge management, has been discussed many times (cf. Schulz 2012), but is still in its infancy in terms of practical implementation in Germany. New impetus has come from the discussion under the heading of Data Driven Government (cf. Fadavian et al. 2019).

The cooperation processes directly affecting the provision of services to citizens and businesses are numerous, especially at municipal level. For this, the term 'intercommunal cooperation' is common. The legal forms of intercommunal cooperation are governed by laws on municipal cooperation. There are two basic forms:

- Several municipalities set up a new organisation with its own legal capacity. The organisation performs specific tasks for all municipalities participating in it and performs the service delivery processes to citizens and businesses.

- Several municipalities sign an agreement mandating one of the participating municipalities to perform a specific task for all the other municipalities involved. The process responsibility then lies with the mandated municipality. 


\subsection{Inter-Organisational Support}

According to the German understanding of the functional definition of administration, it is assumed that every authority is able to fulfil its assigned tasks with its own personnel and material resources. If, however, difficulties arise in individual cases, this should not lead to the task in question not being fulfilled. Due to the public interest in effectively fulfilling administrative tasks, in such a situation the authority must request another authority to provide so-called administrative assistance instead. The authority requested to provide the assistance is obliged to do so. In this case the costs it incurs are reimbursed.

The obligation to give assistance has two limitations: firstly, assistance must be complementary and the actual task must be performed by the authority responsible for the task. Secondly, the assistance may only be provided on a case-by-case basis and not constantly. If an agency constantly needs the help of other agencies to fulfil its tasks, its resources need to be improved.

\subsection{Inter-Organisational Control}

The responsibility of the government to the parliament under German constitutional law presupposes that the government can fulfil this responsibility and have sufficient opportunities to control and influence the performance of the tasks by the administration. This presupposes the right to give orders to the subordinate authorities and civil servants and control of the way in which the assigned tasks are performed. For this purpose, interorganisational procedures for the control of the authorities by the superordinate authority are established. (For control and accountability by administrative courts and courts of audit see Chap. 12.)

In this respect, a distinction must be made between administrative and technical supervision. Administrative supervision is usually understood as the supervision of the structure, internal order, use and distribution of personnel and other resources, as well as general management and personnel matters of the supervised body. Technical supervision refers to the legitimate and appropriate exercise of the technical tasks of the supervised body. The means of technical supervision typically includes the power of the technical supervisory authority to demand information, request submission of files, carry out examinations, issue instructions and, if these are 
not obeyed, take control of the matter by asserting the right of action beyond defined competence.

A third form of supervision besides service and technical supervision is legal supervision. This is limited to reviewing the lawfulness of the decisions of the subordinate authority and does not extend to whether the content of the decision is appropriate. A control restricted to legal supervision usually exists when the subordinate authority has the right of selfgovernment. The most important example is the municipalities.

\subsection{Law}

Processes in the relationship of several administrative units to one another can only be governed by an administrative regulation if there is a joint upper authority or joint body that issues the regulation. An example of a decree by a joint higher authority is the instruction of a ministry to all lower authorities as to how they are to cooperate in certain cases, which deadlines have to be met between the authorities, etc. An example of procedural rules issued by a joint body of several authorities is the Joint Rules of Procedure of the Federal Ministries (GGO), which is adopted by the federal government as a collegiate body. Among other things, it regulates the cooperation and procedure of the federal ministries in the preparation of cabinet bills.

Inter-organisational procedural rules, adopted in the form of an act of parliament concern, for example:

- the regulation of performance-related communication between public authorities (cf. Sect. 5.1.1 above);

- supervision of one authority over the other (cf. Sect. 5.2 above); and

- administrative assistance (cf. Sect. 5.3 above).

\section{LESSONS LEARNED}

As for the question to what extent can the experiences of the German administration be regarded as a reference point for development in other countries, the first thing that applies is the same for all transfers of institutions from the administrative culture of one state into another: the structures and administrative processes are embedded in complex environmental systems of a political, legal, social, economic and cultural nature. This usually excludes a transfer in the sense of a simple takeover. Rather, it 
requires a careful examination of the conditions under which the experiences and institutions of a foreign administrative culture can be made fruitful for one's own structures and administrative processes.

Within this framework, three possible factors from the German experience, which go beyond the general principles of business process and procedure management and are essential for each administration, can be summarised as follows:

- A defining structural attribute of the highly diversified administrative landscape in Germany is its strong involvement in networks and cooperation with other authorities. The examples mentioned above are the creation of learning networks, the joint further development of knowledge management solutions, shared services, in particular in the form of strong intercommunal cooperation, and the obligation to provide mutual assistance to the authorities to fulfil their tasks. This serves to optimise the fulfilment of tasks through mutual learning processes and assistance and the enhancement of synergies.

- Also characteristic of the German understanding of administrative procedures is the legal regulation that puts citizens in a strong position $v i s-\grave{a}$ - $v i s$ the administration. The APA can certainly be described as an 'export hit'. It is the more or less modified basis for the adoption of administrative procedural law codifications in different countries. The reasons for APA's success lie mainly in its systematic clarity and concentration on the key principles and legal institutions. The high degree of abstraction associated with it makes the provisions of administrative procedure law appear flexible and adaptable to different legal systems.

- Especially for administrative systems that are as highly diversified as Germany's, that is in countries where administration is highly decentralised, the German solution, which preserves the autonomy of administrations and their IT systems and provides nevertheless all administrative services via electronic portals with a uniform user account regardless of which authority is competent, can be a helpful reference. 


\section{REFERENCES}

Bundesministerium des Innern, Bundesverwaltungsamt. (2018). Handbuch für Organisationsuntersuchungen und Personalbedarfsermittlung.

Die Bundesregierung. (2019). Change Management-Anwendungshilfe zu Veränderungsprozessen in der öffentlichen Verwaltung. Berlin.

Fadavian, B., Franzen-Paustenbach, D., Rehfeld, D. et al. (2019). Data Driven Government. Berlin.

KGSt. (2011). Von der Prozessoptimierung zum Prozessmanagement (Teil 1) KGStBericht 3/2011. Köln.

Lenk, K. (2012). Die Bedeutung von Prozessen und von Prozessdenken für die Modernisierung der öffentlichen Verwaltung. In U. Schliesky \& S. Schulz (Eds.), Die Erneuerung des arbeitenden Staates (pp. 9-30). BadenBaden: Nomos.

Löffler, E. (2018). Qualitätsmanagement. In S. Veit, C. Reichard, \& G. Wewer (Eds.), Handbuch zur Verwaltungsreform. Wiesbaden: Springer VS.

Martini, M., \& Wiesner, C. (2018). Bürgerkonto, Portalverbund. In S. Veit, C. Reichard, \& G. Wewer (Eds.), Handbuch zur Verwaltungsreform. Wiesbaden: Springer VS.

Materna GmbH, Hochschule Harz. (2013). Wissensmanagement in öffentlichen Verwaltungen.

Müller, C. E., Engewald, B., \& Herr, M. (2019). Freedom of Information in Germany. In D. Dragos, P. Kovač, \& A. Marseille (Eds.), The Laws of Transparency in Action. A European Perspective (pp. 205-254). Basingstoke: Palgrave Macmillan.

Netzwerk Prozessmanagement. (2018). Einführung in das strategische Prozessmanagement der öffentlichen Verwaltung.

Ponce, J. (2005). Good Administration and Administrative Procedures. Indiana Journal of Global Legal Studies, 12(2, Art. 10), 551-588.

Rowe, N., \& Winterhoff, C. (2001). Participants' Rights and Duties in German Administrative Law. European Review of Public Law, 13, 1117-1143.

Schulz, S. (2012). Vernetztes Wissen-Shared Services im Wissensmanagement. In U. Schliesky \& S. Schulz (Eds.), Die Ernenerung des arbeitenden Staates (pp. 113-140). Baden-Baden: Nomos.

Schuppan, T. (2018). Shared Service Center. In S. Veit, C. Reichard, \& G. Wewer (Eds.), Handbuch zur Verwaltungsreform. Wiesbaden: Springer VS. 
Open Access This chapter is licensed under the terms of the Creative Commons Attribution 4.0 International License (http://creativecommons.org/licenses/ by $/ 4.0 /$ ), which permits use, sharing, adaptation, distribution and reproduction in any medium or format, as long as you give appropriate credit to the original author(s) and the source, provide a link to the Creative Commons licence and indicate if changes were made.

The images or other third party material in this chapter are included in the chapter's Creative Commons licence, unless indicated otherwise in a credit line to the material. If material is not included in the chapter's Creative Commons licence and your intended use is not permitted by statutory regulation or exceeds the permitted use, you will need to obtain permission directly from the copyright holder. 